\title{
Relating Freeze-induced Electrolyte Leakage Measurements to Lethal Temperature in Red Raspberry
}

\author{
Leena Lindén and Pauliina Palonen \\ Department of Plant Production, P.O. Box 27, FIN-00014 University of Helsinki, Finland \\ Mikael Lindén \\ Department of Economics, P.O. Box 54, FIN-00014 University of Helsinki, Finland
}

AdDitional INDEX wORDs. cold hardiness, graphical interpolation, $\mathrm{LT}_{50}$, Rubus idaeus, sigmoid functions, woody plants

\begin{abstract}
Seasonal cold hardiness of red raspberry (Rubus idaeus $\mathbf{L}$.) canes was measured by freeze-induced electrolyte leakage test and visual rating of injury. Leakage data were transformed to percentage-adjusted injury values and related to lethal temperature by graphical interpolation and by the midpoint $\left(\mathbf{T}_{50}\right)$ and inflection point $\left(\mathbf{T}_{\text {max }}\right)$ estimates derived from three sigmoid (the logistic, Richards, and Gompertz) functions. $T_{\max }$ estimates produced by Richards and Gompertz functions were corrected further using two different procedures. The 10 leakage-based hardiness indices, thus derived, were compared to lethal-temperature estimates based on visual rating. Graphical interpolation and $T_{\max }$ of the logistic or $T_{50}$ of the Gompertz function yielded lethal-temperature estimates closest to those obtained visually. Also, $T_{\max }$ values of the Gompertz function were well correlated with visual hardiness indices. The Richards function yielded hardiness estimates deviating largely from visual rating. In addition, the Richards function displayed a considerable lack of fit in several data sets. The Gompertz function was preferred to the logistic one as it allows for asymmetry in leakage response. Percentage-adjusted injury data transformation facilitated curve-fitting and enabled calculation of $T_{50}$ estimates.
\end{abstract}

Electrolyte leakage (EL) test is a widely used means to assess the extent of plant injury in relation to temperature stress. The test is based on the principle that damage to cell membranes results in enhanced leakage of solutes into the apoplastic water. Recording the amount of leakage after stress treatments thus provides an estimate of tissue injury.

The EL test is well suited for temperature stress studies, as it is based on alterations in the locus of initial temperature-induced injuries: the active transport system in cell membranes (Palta et al., 1982). However, interpretation of leakage data, from woody plant samples in particular, is often found problematic (Calkins and Swanson, 1990; Keates, 1990). Temperature-stress studies are often aimed at defining the point of lethal injury in the plant or tissue studied, and EL measurements need to be somehow related to the actual level of damage in test material. Herein lies the problem: how to identify the amount of leakage corresponding to lethal injury? Only after solving that can leakage recordings be converted into a comparable hardiness index such as $\mathrm{LT}_{50}$, the temperature at $50 \%$ lethality.

Recordings of EL are usually expressed as percentages of total electrolytes leaking from a heat/freeze-killed sample. The outcoming, relative EL values may be transformed further. Flint et al. (1967) proposed taking into account leakage from nonfrozen control samples that are assigned a value of zero. The EL values thus scaled are called indices of injury. Lim et al. (1998) took the data transformation one step further by adjusting the indices of injury for EL from totally freeze-injured samples. The resulting, percentage-adjusted injury values range between $0 \%$ and $100 \%$.

Often, the $50 \%$ level of relative EL, or index of injury, is simply

Received for publication 28 Sept. 1999. Accepted for publication 11 Apr. 2000. This study was supported financially by Tiura Agricultural Research Foundation, Jenny and Antti Wihuri Foundation, and the Academy of Finland. We sincerely thank Rajeev Arora for valuable suggestions and constructive criticism regarding an earlier version of this manuscript. The cost of publishing this paper was defrayed in part by the payment of page charges. Under postal regulations, this paper therefore must be hereby marked advertisement solely to indicate this fact. equaled to 50\% sample lethality (e.g., Arora et al., 1992; Boorse et al., 1998; Grossnickle, 1992), and the corresponding temperature is determined by graphic or regression methods from the leakage vs. test-temperature plot. However, while measuring leakage from well-acclimated woody plants, the maximum values obtained at the lowest test temperatures often remain well below the $50 \%$ level (Hadley and Amundson, 1992; Repo et al., 1996; Sutinen et al., 1992; Wiemken et al., 1996).

Because of the seasonal variation in EL of freeze-stressed needles of Austrian pine (Pinus nigra Arnold) and red pine (Pinus resinosa Ait.), Sutinen et al. (1992) derived the critical temperature graphically, employing the arithmetic mean of leakage between noninjured and freeze-damaged tissues as the critical point of EL. The procedure yielded lethal-temperature estimates correlated with visual observations for most of the year (Sutinen et al., 1992). A similar approach was applied by Arora et al. (1998) to determine the $\mathrm{LT}_{50}$ of geranium (Pelargonium $\times$ hortorum L. H. Bail.) leaves and by Rajashekar et al. (1982) to define the killing temperature for pear (Pyrus L. sp.) stems.

The critical point of electrolyte leakage, and the corresponding lethal temperature, may also be predicted by empirical mathematical models. The basic assumptions are that plant response to freeze stress is sigmoid and bounded by a lower and upper asymptote, and that the lethal point equals the inflection point of a sigmoid function, i.e., to the point where the rate of change in plant response is highest.

Conventionally, EL data are modeled using the symmetric, logistic function (e.g., Ingram and Buchanan, 1984; Repo et al., 1996; Zhu and Liu, 1987), with an inflection point located exactly halfway between the upper and lower asymptotes and thus, equal to the midpoint of the curve. However, von Fircks and Verwijst (1993) mentioned that use of a symmetric function may lead to biased interpretations of freeze-response data, and recommended use of the nonsymmetric Richards function rather than the logistic one. The Richards function allows for the inflection point to disperse from the midpoint.

In a study with five woody plant taxa, the Richards function 
Table 1. Calculation of lethal-temperature estimates. ${ }^{\mathrm{z}}$

\begin{tabular}{|c|c|c|c|c|c|}
\hline Function & Equation & $\mathrm{T}_{50}^{\mathrm{y}}$ & $\mathrm{T}_{\max }^{\mathrm{x}}$ & $\mathrm{T}_{\text {corr1 }}{ }^{\mathrm{w}}$ & $\mathrm{T}_{\text {corr2 }}^{\mathrm{v}}$ \\
\hline Logistic & $100[1+\exp (b-c T)]^{-1}$ & $\mathrm{~b} / \mathrm{c}$ & $\mathrm{b} / \mathrm{c}$ & --- & --- \\
\hline Richards & $100[1+\exp (b-c T)]^{-1 / d}$ & $(1 / c)\left[b-\ln \left(2^{d}-1\right)\right]$ & $(1 / c)[b-\ln (d)]$ & $(1 / c)[b-\ln (d)-d-1]$ & $(1 / \mathrm{c})\left[\mathrm{b}-\ln \left[\left(100 / \mathrm{I}_{\max }\right)^{\mathrm{d}}-1\right]\right]$ \\
\hline Gompertz & $100 \exp [-\mathrm{b} \exp (-\mathrm{cT})]$ & $-(1 / b)[\ln \ln (2)-\ln (b)]$ & $(1 / \mathrm{c}) \ln (\mathrm{b})$ & $(1 / c)[\ln (b)-1]$ & $-(1 / \mathrm{c}) \ln \left[(1 / \mathrm{b}) \ln \left(100 / \mathrm{I}_{\max }\right)\right]$ \\
\hline
\end{tabular}

${ }^{\mathrm{z}}$ Where $\mathrm{b}, \mathrm{c}$, and $\mathrm{d}$ are function parameters, $\exp =$ exponential, $\mathrm{I}_{\max }=$ percentage-adjusted injury at the inflection point, and $\mathrm{T}=$ freezing temperature . yTemperature at the $50 \%$ adjusted injury level.

${ }^{\mathrm{x}}$ Temperature corresponding to the highest rate of change in percentage-adjusted injury.

wTemperature obtained by the first correction method.

${ }^{\mathrm{v}}$ Temperature obtained by the second correction method.

inflection point failed to estimate properly the critical level of leakage (Anisko and Lindstrom,1995). Therefore, the authors developed a correction method for interpreting leakage vs. temperature curves: they determined the lethal-temperature range by a point of interception of the lower asymptote with a line tangential to the inflection point of a fitted curve. The procedure is based on the assumption that the transition from the living to the dead state coincides with the initial increase rather than the highest rate in EL (Anisko and Lindstrom, 1995).

Recently, Lim et al. (1998) compared two asymmetric sigmoid models, Richards and Gompertz functions, to estimate the freezing tolerance of rhododendron (Rhododendron L. sp.) leaves. No significant difference was found between the two functions, but the Gompertz function was preferred due to its slightly better fit and smaller number of parameters. Lim et al. (1998) also made a comparison between two hardiness indices, the midpoint and the inflection point, estimated from the fitted curves. They selected the inflection point as the hardiness criterion and considered it physiologically more descriptive than the midpoint estimate.

Presently, there are only a few reports on applying asymmetric functions to fit EL data, probably due to the complexity of the curvefitting process. To our knowledge, the report by Anisko and Lindstrom (1995) is the only one where leakage response for woody stem samples is described using an asymmetric function. Therefore, the following research was undertaken to compare the graphic and parametric curve-fitting methods of relating EL data from woody stems to lethal temperature. Our objective was to develop a reliable method for defining the $\mathrm{LT}_{50}$ on the basis of leakage measurements. The leakage data were obtained from controlled-freezing tests conducted on overwintering red raspberry (Rubus idaeus) canes. Hardiness indices estimated by graphical interpolation and by applying the logistic, Richards, and Gompertz functions to leakage data were compared with lethal-temperature estimations based on visual rating.

\section{Materials and Methods}

Plant material. One-year-old canes of raspberry cultivars Maurin Makea, Ottawa, and Muskoka were collected from a cultivar trial at the Agricultural Research Centre, Häme Research

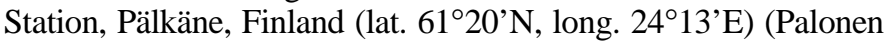
and Lindén, 1999). Canes were sampled on six dates during Winter 1996-97: 7 Oct., 7 Nov., 1 Dec., 3 Feb., 3 Mar., and 10 Apr. Sample canes were sectioned into pieces $15-20 \mathrm{~cm}$ long, except for the terminal and basal 20-30 cm of each cane, which were discarded. The cane sections were packed in polyethylene bags, and shipped on ice in Styrofoam boxes to the Department of Plant Production, University of Helsinki.

CONTROLLED FREEZING TESTS. The freezing treatments were initiated on the day of sampling. Samples were randomly assigned to predetermined test temperatures, wrapped in moist paper towels to ensure ice nucleation and re-closed in polyethylene bags. Three replicates were sampled for each cultivar and test temperature.

Freezing was accomplished in a walk-in controlled-climate chamber (Weiss 2600/45...5 DU-Pi; Weiss Umwelttechnik, Germany) according to a stepwise lowering freezing program starting from the prevailing outdoor temperature and with a test temperature interval of $5^{\circ} \mathrm{C}$. The freezing rate was $5^{\circ} \mathrm{C} \cdot \mathrm{h}^{-1}$, and the duration of each test temperature $30 \mathrm{~min}$. There were seven test temperatures; in October, November, and April the test temperatures ranged from -5 to $-35^{\circ} \mathrm{C}$; in December, February, and March the range of test temperatures was -15 to $-45^{\circ} \mathrm{C}$. Control shoots were maintained at $0{ }^{\circ} \mathrm{C}$ during freezing. Samples were thawed at $0{ }^{\circ} \mathrm{C}$ in closed Styrofoam boxes for 15 to $24 \mathrm{~h}$.

INJURY ASSESSMENTS. The EL tests were started immediately after thawing by cutting three internodal, $1-\mathrm{cm}$ sections from each sample. The sections were rinsed with ultrapure water (Milli-Q PF Plus water purification systems, Millipore Co., Bedford, Mass.) to remove exogenous electrolytes and placed into $35-\mathrm{mL}$ test tubes containing $8 \mathrm{~mL}$ of ultrapure water. The tubes were capped with aluminium foil and incubated at room temperature $\left(+22^{\circ} \mathrm{C}\right)$ under constant shaking at $160 \mathrm{rpm}$.

After 21 h of incubation, the electrical conductivity of the bathing solutions $\left(\mathrm{L}_{1}\right)$ was measured using a Jenway 4020 conductivity meter (Jenway, Felsted, Essex, U.K.). Samples were killed by autoclaving the tubes at $121^{\circ} \mathrm{C}$ for $15 \mathrm{~min}$, re-incubated as before, and measured for the final conductivity values $\left(\mathrm{L}_{2}\right)$. The conductivity measurements were converted into indices of injury according to Flint et al. (1967): Index of injury $y_{(\mathrm{T})}=100 \times\left(\mathrm{R}_{\mathrm{T}}-\mathrm{R}_{0}\right) /\left(1-\mathrm{R}_{0}\right) ; \mathrm{R}_{\mathrm{T}}$ $=\mathrm{L}_{1 \mathrm{~T}} / \mathrm{L}_{2} \mathrm{~T} ; \mathrm{R}_{0}=\mathrm{L}_{1 \mathrm{C}} / \mathrm{L}_{2 \mathrm{C}}$, where $\mathrm{L}_{1 \mathrm{~T}}$ and $\mathrm{L}_{2 \mathrm{~T}}$ are the initial and final leakage values for a sample exposed to temperature $\mathrm{T}$, and $\mathrm{L}_{1 \mathrm{C}}$, and $\mathrm{L}_{2 \mathrm{C}}$ are the corresponding values measured from respective control samples. EL data, thus transformed, starts from 0\%. To spread EL values between $0 \%$ and $100 \%$, the data were adjusted further for leakage from totally injured samples as suggested by Lim et al. (1998): Percentage-adjusted injury ${ }_{(\mathrm{T})}=\left[\right.$ index of injury $_{(\mathrm{T})} /$ index of injury $\left._{(\text {T lowest }}\right] \times 100$, where index of injury ${ }_{(\mathrm{T})}$ is the value obtained at respective freeze-treatment temperature, and index of injury ${ }_{(\mathrm{T}}$ lowest) is that obtained at the lowest test temperature $\left(-35 /-45^{\circ} \mathrm{C}\right)$.

The remaining samples were maintained in polyethylene bags at room temperature for 1 week to allow oxidation of tissues before visual examination of injury. Three pieces of each sample were evaluated for survival by removing a thin layer of cortical tissue with a surgical knife and assessing injuries in the vascular regions under a dissecting microscope. A two-class rating was used; canes showing brown discoloration in the vascular tissues were rated as dead while those remaining green were rated as alive. The visual observations revealed that at each sampling date the canes exposed to the highest test temperature were uninjured while those that had experienced the most severe treatment, were dead. 
Data ANaLYSes. The mortality data produced by visual ratings were analyzed by logit models as described by Lindén et al. (1996). A separate freeze-death probability model was fit for each sampling time, with treatment temperatures, cultivars, and interactions between them as explanatory variables. The computer software used was the GENMOD procedure of SAS (SAS Inst., Inc., Cary, N.C.) with maximum likelihood method for estimating parameters. The log-likelihood ratio test was used for measuring model goodness of fits. The lethal temperatures $\left(\mathrm{LT}_{50} \mathrm{~s}\right)$ were determined using logit model parameters.

The percentage-adjusted injury data, obtained through EL measurements, were analyzed separately for each cultivar and sampling time. The lethal temperature for each data set was first defined by graphical interpolation following the method suggested by Sutinen et al. (1992). Due to the percentage-adjusted injury data transformation, mean leakage was always $50 \%$. The corresponding temperature, representing the critical level of freezing stress, was derived graphically from plots of the percentage-adjusted injury vs. temperature.

The logistic, Richards, and Gompertz functions were fitted to the percentage-adjusted injury data using GAUSS 3.2 software (Aptech Systems, Maple Valley, Wash.) with the maximum likelihood method of estimating parameters. As the percentage-adjusted injury data are spread between $0 \%$ and $100 \%$, the low-temperature asymptotic parameter of the three functions could be fixed to $100 \%$. The modified logistic, Richards, and Gompertz functions are illustrated in Table 1. Model goodnesses of fit were assessed by adjusted multiple correlation coefficients and log-likelihood ratio test statistics (Eliason, 1993).

The lethal-temperature estimates, $\mathrm{T}_{50}$ and $\mathrm{T}_{\max }$, were calculated on the basis of estimated parameter values for each function (Table 1). $T_{50}$ represents the temperature corresponding to the $50 \%$ adjusted injury level, and $\mathrm{T}_{\max }$ is the temperature at the inflection point of each nonlinear curve.

The lethal temperatures were also determined by further manipulating the Richards and Gompertz functions with two correction methods (Table 1). The first one, suggested by Anisko and Lindstrom (1995), determines the corrected lethal-temperature value by using the first-order approximation of Taylor series. To approximate the percentage-adjusted injury (I) value at the inflection point, we define $\mathrm{I}$ at zero temperature $\left(\mathrm{I}_{\mathrm{T}}(0)\right)$ as $\mathrm{I}_{\mathrm{T}}(0) \approx \mathrm{I}_{\max }+(\mathrm{dI} / \mathrm{dT})_{\max }(0$ - $T_{\max }$ ), where $I_{\max }$ and $T_{\max }$ are percentage-adjusted injury and temperature at the inflection point of the appropriate function. Because $\mathrm{I}_{\mathrm{T}}(0)=0$, we have $\mathrm{T}_{\max }-\mathrm{I}_{\max } /(\mathrm{dI} / \mathrm{dT})_{\max }>\mathrm{T}_{\max }$, and thus the corrected value $\mathrm{T}_{\text {corr }}$ is obtained as $\mathrm{T}_{\text {corr } 1}=\mathrm{T}_{\max }-\mathrm{I}_{\max } /(\mathrm{dI} / \mathrm{dT})_{\max }$.

The correction method of Anisko and Lindstrom (1995), described above, will most often generate a hardiness index value that is higher (warmer temperature) than that given by the original inflection point. In addition, the correction may often be too large. Therefore, we wanted to introduce a more general correction approach by applying the second-order approximation of MaclaurinTaylor series. First, the relationship between percentage-adjusted injury value at the inflection point and at the upper asymptote was defined as $t: t=I_{\max } / I_{\text {upper }}$. The value of $t$ lies in the range: $0<t<1$. The second-order approximation of Maclaurin-Taylor series gives $\ln (1+\mathrm{t}) \approx \mathrm{t}-\left(\mathrm{t}^{2} / 2\right)$.

The relationship between percentage-adjusted injury value at a corrected point $\left(\mathrm{I}_{\text {corr } 2}\right)$ and at the upper asymptote $\left(\mathrm{I}_{\text {upper }}\right)$ was defined as $\mathrm{t}_{0}: \mathrm{t}_{0}=\mathrm{I}_{\text {corr } 2} / \mathrm{I}_{\text {upper. }} \mathrm{t}_{0}$ can be approximated as $\mathrm{t}_{0}=\mathrm{t}-\left(\mathrm{t}^{2} / 2\right)$.

By multiplying this with $\mathrm{I}_{\text {upper, }}$, an estimate for $\mathrm{I}_{\text {corr }}$ is obtained: $I_{\text {corr } 2}=I_{\max }-\left(I_{\max }\right)^{2} /\left(2 I_{\text {upper }}\right)=I_{\max }\left[1-I_{\max } /\left(2 I_{\text {upper }}\right)\right]$.

Thus, $\mathrm{I}_{\text {corr } 2}$ is computed easily when estimates for $\mathrm{I}_{\max }$ and $\mathrm{I}_{\text {upper }}$ are known. The corresponding $\mathrm{T}_{\text {corr } 2}$ value is obtained by using the estimated parameter values of the appropriate nonlinear function.

Table 2. Goodness-of-fit test statistics for the three nonlinear functions used to fit electrolyte leakage data from raspberry canes.

\begin{tabular}{|c|c|c|c|c|c|c|}
\hline \multirow{2}{*}{$\begin{array}{l}\text { Sampling time } \\
\text { and cultivar }\end{array}$} & \multicolumn{3}{|c|}{ Adjusted $R^{2}$} & \multicolumn{3}{|c|}{ Log-likelihood ratio test statistic } \\
\hline & Logistic & Richards & Gompertz & Logistic & Richards & Gompertz \\
\hline \multicolumn{7}{|l|}{ October } \\
\hline Maurin Makea & 0.90 & 0.89 & 0.88 & 154.5 & 150.6 & 146.7 \\
\hline Ottawa & 0.90 & 0.18 & 0.88 & 157.8 & 13.5 & 144.1 \\
\hline Muskoka & 0.89 & 0.88 & 0.87 & 132.2 & 128.5 & 122.7 \\
\hline \multicolumn{7}{|l|}{ November } \\
\hline Maurin Makea & 0.89 & 0.88 & 0.87 & 152.3 & 144.7 & 140.2 \\
\hline Ottawa & 0.82 & 0.27 & 0.80 & 111.4 & 19.9 & 103.3 \\
\hline Muskoka & 0.81 & 0.11 & 0.76 & 109.2 & 7.4 & 93.3 \\
\hline \multicolumn{7}{|l|}{ December } \\
\hline Maurin Makea & 0.83 & 0.08 & 0.79 & 123.1 & 5.5 & 108.0 \\
\hline Ottawa & 0.84 & 0.10 & 0.84 & 132.8 & 8.0 & 132.0 \\
\hline Muskoka & 0.81 & 0.81 & 0.80 & 120.2 & 118.3 & 117.0 \\
\hline \multicolumn{7}{|l|}{ February } \\
\hline Maurin Makea & 0.00 & 0.00 & 0.19 & 0.4 & 0.0 & 15.3 \\
\hline Ottawa & 0.51 & 0.16 & 0.50 & 49.0 & 11.8 & 47.3 \\
\hline Muskoka & 0.48 & 0.16 & 0.48 & 47.1 & 12.7 & 45.8 \\
\hline \multicolumn{7}{|l|}{ March } \\
\hline Maurin Makea & 0.69 & 0.69 & 0.68 & 85.5 & 83.8 & 81.8 \\
\hline Ottawa & 0.83 & 0.02 & 0.76 & 127.6 & 1.3 & 101.7 \\
\hline Muskoka & 0.81 & 0.08 & 0.79 & 116.6 & 5.9 & 111.8 \\
\hline \multicolumn{7}{|l|}{ April } \\
\hline Maurin Makea & 0.78 & 0.21 & 0.76 & 104.7 & 16.7 & 98.8 \\
\hline Ottawa & 0.36 & 0.06 & 0.34 & 30.4 & 4.5 & 28.4 \\
\hline Muskoka & 0.75 & 0.16 & 0.73 & 95.4 & 11.9 & 89.2 \\
\hline \multicolumn{4}{|c|}{ Critical value of log-likelihood ratio at $P \leq 0.05$} & 6.0 & 7.8 & 6.0 \\
\hline
\end{tabular}


Table 3. Seasonal cold hardiness $\left({ }^{\circ} \mathrm{C}\right)$ of three raspberry cultivars as predicted by visual rating of injury and 10 methods of interpreting electrolyte leakage measurements. ${ }^{\mathrm{z}}$

\begin{tabular}{|c|c|c|c|c|c|c|c|c|c|c|c|}
\hline \multirow{2}{*}{$\begin{array}{l}\text { Sampling time } \\
\text { and cultivar }\end{array}$} & \multirow{2}{*}{$\begin{array}{l}\text { Visual } \\
\text { rating }^{y}\end{array}$} & \multirow{2}{*}{$\begin{array}{c}\text { Graphic } \\
\text { interpolation }^{\mathrm{x}}\end{array}$} & \multirow{2}{*}{$\begin{array}{c}\text { Logistic } \\
\mathrm{T}_{\max }{ }^{\mathrm{w}} \\
\end{array}$} & \multicolumn{4}{|c|}{ Richards } & \multicolumn{4}{|c|}{ Gompertz } \\
\hline & & & & $\mathrm{T}_{50}^{\mathrm{v}}$ & $\mathrm{T}_{\max }$ & $\mathrm{T}_{\text {corrl }}{ }^{u}$ & $\mathrm{~T}_{\text {corr2 }}{ }^{\mathrm{t}}$ & $\mathrm{T}_{50}$ & $\mathrm{~T}_{\max }$ & $\mathrm{T}_{\text {corrl }}$ & $\mathrm{T}_{\text {corr2 }}$ \\
\hline \multicolumn{12}{|l|}{ October } \\
\hline Maurin Makea & -19.9 & -15.2 & -14.2 & -25.6 & -24.3 & -15.6 & -22.4 & -13.4 & -10.7 & -8.9 & -9.3 \\
\hline Ottawa & -20.1 & -20.3 & -17.3 & -19.1 & -24.9 & -12.2 & -18.6 & -16.2 & -13.1 & -11.0 & -11.3 \\
\hline Muskoka & -17.5 & -17.6 & -16.0 & -29.4 & -27.8 & -17.9 & -25.7 & -14.8 & -11.9 & -10.0 & -10.3 \\
\hline \multicolumn{12}{|l|}{ November } \\
\hline Maurin Makea & -22.5 & -23.3 & -23.0 & -43.7 & -41.6 & -30.9 & -39.3 & -22.2 & -18.9 & -17.6 & -17.0 \\
\hline Ottawa & -24.9 & -22.6 & -21.0 & -22.7 & -27.8 & -13.9 & -21.9 & -20.0 & -16.2 & -13.9 & -14.1 \\
\hline Muskoka & -25.1 & -26.8 & -24.0 & -25.6 & -32.1 & -17.2 & -25.0 & -23.0 & -18.4 & -15.1 & -15.9 \\
\hline \multicolumn{12}{|l|}{ December } \\
\hline Maurin Makea & -27.5 & -31.7 & -31.2 & -31.1 & -30.9 & -25.3 & -29.5 & -30.1 & -27.7 & -27.6 & -26.3 \\
\hline Ottawa & -30.3 & -31.4 & -31.0 & -31.1 & -31.6 & -23.9 & -29.5 & -30.3 & -27.9 & -27.8 & -26.5 \\
\hline Muskoka & -28.1 & -30.3 & -28.0 & -52.0 & -49.5 & -37.5 & -47.0 & -27.0 & -23.3 & -22.1 & -21.2 \\
\hline \multicolumn{12}{|l|}{ February } \\
\hline Maurin Makea & -35.8 & -40.4 & --- & --- & --- & --- & --- & -46.7 & -43.0 & -42.9 & -40.9 \\
\hline Ottawa & -31.4 & -33.5 & -28.9 & -30.0 & -33.7 & -17.3 & -28.1 & -27.6 & -23.8 & -22.7 & -21.7 \\
\hline Muskoka & -28.3 & -29.0 & -30.2 & -30.5 & -29.2 & -24.4 & -28.2 & -30.5 & -27.9 & -27.7 & -26.4 \\
\hline \multicolumn{12}{|l|}{ March } \\
\hline Maurin Makea & -25.3 & -32.3 & -28.7 & -57.8 & -54.9 & -37.6 & -51.2 & -27.5 & -22.7 & -20.1 & -20.0 \\
\hline Ottawa & -26.4 & -30.0 & -30.0 & -30.0 & -30.0 & -27.5 & -29.4 & -29.2 & -26.9 & -26.8 & -25.6 \\
\hline Muskoka & -26.4 & -32.7 & -32.3 & -32.3 & -32.3 & -25.1 & -30.5 & -31.3 & -28.6 & -28.5 & -27.1 \\
\hline \multicolumn{12}{|l|}{ April } \\
\hline Maurin Makea & -22.4 & -25.8 & -25.6 & -26.7 & -29.9 & -18.4 & -25.6 & -25.0 & -22.3 & -21.9 & -20.8 \\
\hline Ottawa & -25.8 & -25.6 & -25.0 & -25.6 & -26.7 & -20.8 & -24.8 & -24.1 & -21.7 & -21.5 & -20.4 \\
\hline Muskoka & -23.6 & -30.5 & -28.5 & -28.5 & -28.5 & -20.4 & -26.4 & -27.9 & -25.6 & -25.4 & -24.3 \\
\hline
\end{tabular}

${ }^{\mathrm{z} E m p t y ~ c e l l s ~ i n d i c a t e ~ c a s e s ~ w h e r e ~ p a r a m e t e r ~ e s t i m a t e s ~ w e r e ~ n o t ~ o b t a i n e d ~ d u e ~ t o ~ n o n c o n v e r g e n c e ~ o f ~ m a x i m u m ~ l i k e l i h o o d ~ m e t h o d . ~}$

$\mathrm{yLT}_{50}$ determined using logit models.

${ }^{\mathrm{x}} \mathrm{LT}_{50}$ derived from plot of percentage-adjusted injury vs. temperature.

${ }^{\text {w}}$ Temperature corresponding to the highest rate of change in percentage-adjusted injury.

vTemperature at the $50 \%$ adjusted injury level.

uTemperature obtained by the first correction method.

${ }^{\mathrm{t}}$ Temperature obtained by the second correction method.

Both correction methods were applied to Richards as well as Gompertz function. Applying these methods to each of the adjusted injury data sets yielded 10 lethal-temperature estimates per cultivar per month. These leakage-based hardiness values were compared to the visual $\mathrm{LT}_{50} \mathrm{~s}$ by calculating the mean and absolute differences between them and by conducting a partial correlation analysis (holding month constant) with SAS CORR Procedure (SAS Inst., Inc., Cary, N.C.).

\section{Results}

On the basis of log-likelihood test statistics, each of the monthly logit models fitted the mortality data adequately (data not presented). As none of the interaction (temperature $\times$ cultivar) terms proved significant, only the main effects (temperature and cultivar) were included in the final models used for estimating the $\mathrm{LT}_{50}$ values.

The logistic and Gompertz functions were well fitted to the leakage response with significant test statistics, except for the February data sets (Table 2). The Richards function, however, displayed more lack of fit, as indicated by model statistics (Table 2). Furthermore, fitting the Richards function to the February data for 'Maurin Makea' failed, due to the non-convergence of maximum likelihood method. Because of the difficulties in fitting the injury values of 'Maurin Makea' in February, the results for this data set

were not included in lethal temperature comparisons.

The pattern of cold acclimation was similar in the three raspberry cultivars studied (Table 3). Cold hardiness of canes increased from October to February, followed by deacclimation in March and April (Table 3). On the basis of visual rating, the three cultivars differed from each other at two dates: in October both 'Maurin Makea' and 'Ottawa' were hardier than 'Muskoka' $(P<0.001)$. In February, when maximal acclimation was attained, 'Maurin Makea' was significantly more cold resistant than 'Muskoka' $(P<0.001)$.

Of the 10 procedures compared, graphical interpolation and using $\mathrm{T}_{\max }$ of the logistic or $\mathrm{T}_{50}$ of the Gompertz function yielded lethal-temperature estimates closest to visual $\mathrm{LT}_{50} \mathrm{~s}$ (Table 4). The same three methods were best correlated to visual hardiness estimates (Table 5). Even the $\mathrm{T}_{\max }$ of the Gompertz function produced lethal-temperature estimates fairly well correlated with those obtained visually (Table 5). The $\mathrm{T}_{\max }$ estimates differed, however, more from visual $\mathrm{LT}_{50} \mathrm{~s}$ than the $\mathrm{T}_{50}$ values of the same function or the $T_{\max }$ estimates given by the logistic curve (Table 4). The two correction methods, applied in connection with the Gompertz function, did not provide any improvement in lethal-temperature prediction (Tables 4 and 5).

Using the $T_{50}$ or $T_{\max }$ of the Richards function resulted in hardiness estimates largely deviating from visual $\mathrm{LT}_{50} \mathrm{~s}(\mathrm{Table} 4)$. In comparison with the $\mathrm{T}_{\max }$ estimates, the correction procedures brought the lethal-temperature values slightly closer to visual evaluations (Table 4). However, there were no statistically significant correlations between any of the Richards function-based estimations and visual $\mathrm{LT}_{50}$ s (Table 5). 
Table 4. Differences between raspberry cold hardiness estimates $\left({ }^{\circ} \mathrm{C}\right)$ obtained by visual rating of injury $\left(\mathrm{LT}_{50} \mathrm{~s}\right.$ determined with logit models) and the 10 different methods of interpreting electrolyte leakage measurements., ${ }^{z, y}$

\begin{tabular}{|c|c|c|c|c|c|c|c|c|c|c|}
\hline \multirow{2}{*}{$\begin{array}{l}\text { Sampling time } \\
\text { and cultivar }\end{array}$} & \multirow{2}{*}{$\begin{array}{c}\text { Graphic } \\
\text { interpolation }^{\mathrm{x}}\end{array}$} & \multirow{2}{*}{$\begin{array}{c}\text { Logistic } \\
\mathrm{T}_{\max }{ }^{\mathrm{w}} \\
\end{array}$} & \multicolumn{4}{|c|}{ Richards } & \multicolumn{4}{|c|}{ Gompertz } \\
\hline & & & $\mathrm{T}_{50}{ }^{\mathrm{v}}$ & $\mathrm{T}_{\max }$ & $\mathrm{T}_{\text {corr1 }}^{\mathrm{u}}$ & $\mathrm{T}_{\text {corr2 }}{ }^{\mathrm{t}}$ & $\mathrm{T}_{50}$ & $\mathrm{~T}_{\max }$ & $\mathrm{T}_{\text {corrl }}$ & $\mathrm{T}_{\text {corr2 }}$ \\
\hline \multicolumn{11}{|l|}{ October } \\
\hline Maurin Makea & -4.7 & -5.7 & 5.7 & 4.3 & -4.3 & 2.4 & -6.6 & -9.2 & -11.0 & -10.7 \\
\hline Ottawa & 0.2 & -2.8 & -1.0 & 4.8 & -7.9 & -1.4 & -3.9 & -7.0 & -9.1 & -8.7 \\
\hline Muskoka & 0.1 & -1.6 & 11.9 & 10.3 & 0.4 & 8.2 & -2.7 & -5.6 & -7.5 & -7.2 \\
\hline \multicolumn{11}{|l|}{ November } \\
\hline Maurin Makea & 0.8 & 0.5 & 21.2 & 19.1 & 8.4 & 16.8 & -0.3 & -3.6 & -4.9 & -5.5 \\
\hline Ottawa & -2.3 & -3.9 & -2.3 & 2.9 & -11.1 & -3.1 & -5.0 & -8.7 & -11.1 & -10.8 \\
\hline Muskoka & 1.7 & -1.1 & 0.5 & 7.0 & -7.9 & -0.1 & -2.1 & -6.7 & -10.0 & -9.3 \\
\hline \multicolumn{11}{|l|}{ December } \\
\hline Maurin Makea & 4.2 & 3.7 & 3.6 & 3.4 & -2.2 & 2.0 & 2.6 & 0.2 & 0.1 & -1.2 \\
\hline Ottawa & 1.1 & 0.7 & 0.9 & 1.3 & -6.4 & -0.8 & 0.0 & -2.4 & -2.5 & -3.8 \\
\hline Muskoka & 2.2 & -0.1 & 23.9 & 21.4 & 9.4 & 18.9 & -1.0 & -4.8 & -6.0 & -6.9 \\
\hline \multicolumn{11}{|l|}{ February } \\
\hline Maurin Makea & --- & --- & --- & --- & --- & --- & --- & --- & --- & --- \\
\hline Ottawa & 2.1 & -2.5 & -1.4 & 2.3 & -14.1 & -3.3 & -3.8 & -7.6 & -8.7 & -9.7 \\
\hline Muskoka & 0.7 & 2.0 & 2.2 & 0.9 & -3.9 & -0.1 & 2.2 & -0.4 & -0.6 & -1.9 \\
\hline \multicolumn{11}{|l|}{ March } \\
\hline Maurin Makea & 7.0 & 3.4 & 32.5 & 29.6 & 12.4 & 25.9 & 2.3 & -2.5 & -5.1 & -5.2 \\
\hline Ottawa & 3.6 & 3.6 & 3.6 & 3.6 & 1.1 & 3.0 & 2.9 & 0.5 & 0.5 & -0.8 \\
\hline Muskoka & 6.3 & 5.9 & 5.9 & 5.9 & -1.3 & 4.1 & 4.9 & 2.2 & 2.1 & 0.7 \\
\hline \multicolumn{11}{|l|}{ April } \\
\hline Maurin Makea & 3.4 & 3.2 & 4.3 & 7.5 & -4.1 & 3.2 & 2.6 & -0.1 & -0.5 & -1.6 \\
\hline Ottawa & -0.2 & -0.8 & -0.2 & 0.9 & -5.0 & -1.0 & -1.7 & -4.1 & -4.3 & -5.4 \\
\hline Muskoka & 6.9 & 4.9 & 4.9 & 4.9 & -3.3 & 2.8 & 4.3 & 1.9 & 1.8 & 0.6 \\
\hline Mean & 1.9 & 0.6 & 6.8 & 7.7 & -2.3 & 4.6 & -0.3 & -3.4 & -4.5 & -5.1 \\
\hline Mean of absolute differences & 2.8 & 2.7 & 7.4 & 7.7 & 6.1 & 5.7 & 2.9 & 4.0 & 5.0 & 5.3 \\
\hline
\end{tabular}

${ }^{\mathrm{z}}$ The difference gets a negative value in case visual rating yields a lower temperature than leakage test.

'February values for 'Maurin Makea' are not included due to failures in curve fitting.

${ }^{\mathrm{x}} \mathrm{LT}_{50}$ derived from plot of percentage-adjusted injury vs. temperature.

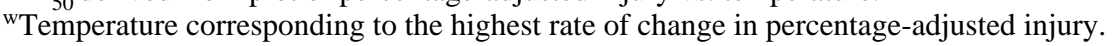

vTemperature at the $50 \%$ adjusted injury level.

uTemperature obtained by the first correction method.

tTemperature obtained by the second correction method.

The monthly freezing tests revealed seasonal changes in raspberry cane leakage response (Fig. 1). After the first sampling in October, a decrease in the maximum level of EL and a concomitant flattening of the temperature-response curve was observed. In April, the level of freeze-induced EL was lowest.

\section{Discussion}

Measuring EL is a common tool in plant cold hardiness research, and refinements to the technique continue to be made. In our study, the leakage recordings for freeze-stressed raspberry canes were transformed to percentage-adjusted injury data. The transformation

enables calculation of $\mathrm{T}_{50}$ estimates and facilitates curve-fitting as the initial and final EL values can be fixed to 0 and 100. The lethal temperature was equally well predicted by graphical interpolation as by $\mathrm{T}_{\max }$ of the logistic function and $\mathrm{T}_{50}$ of the Gompertz function.

We applied the graphical method suggested by Sutinen et al. (1992), where the critical leakage value is derived from the arithmetical mean between noninjured and freeze-killed samples. The mean leakage coincides with the $50 \%$ adjusted injury value and hence, the graphical interpolation yields an approximation for $\mathrm{T}_{50}$. The graphical method is easily applicable and independent of data transformation. However, there is an inclination to subjective bias errors and the degree of confidence associated with the lethal-temperature value can not be estimated.

Thus far, most researchers applying mathematical modeling

Table 5. Pearson's partial correlation coefficients between visual $\mathrm{LT}_{50}$ determined with logit models, and the 10 leakage-based hardiness estimations.

\begin{tabular}{|c|c|c|c|c|c|c|c|c|c|c|}
\hline & \multirow{2}{*}{$\begin{array}{l}\text { Graphic } \\
\text { interpolation }^{\mathrm{z}}\end{array}$} & \multirow{2}{*}{$\begin{array}{c}\text { Logistic } \\
\mathrm{T}_{\max }^{\mathrm{y}}\end{array}$} & \multicolumn{4}{|c|}{ Richards } & \multicolumn{4}{|c|}{ Gompertz } \\
\hline & & & $\mathrm{T}_{50}{ }^{\mathrm{x}}$ & $\mathrm{T}_{\max }$ & $\mathrm{T}_{\text {corr1 }}{ }^{\mathrm{w}}$ & $\mathrm{T}_{\text {corr2 }}{ }^{\mathrm{v}}$ & $\mathrm{T}_{50}$ & $\mathrm{~T}_{\max }$ & $\mathrm{T}_{\text {corr } 1}$ & $\mathrm{~T}_{\text {corr } 2}$ \\
\hline Visual $\mathrm{LT}_{50}$ & 0.842 & 0.826 & 0.235 & 0.292 & 0.348 & 0.294 & 0.821 & 0.785 & 0.749 & 0.758 \\
\hline$P$ & 0.0001 & 0.0001 & 0.3819 & 0.2723 & 0.1861 & 0.2688 & 0.0001 & 0.0003 & 0.0008 & 0.0007 \\
\hline
\end{tabular}

${ }^{\mathrm{Z}} \mathrm{LT}_{50}$ determined from plot of percentage-adjusted injury vs. temperature.

yTemperature corresponding to the highest rate of change in percentage-adjusted injury.

${ }^{x}$ Temperature at the $50 \%$ adjusted injury level.

wTemperature obtained by the first correction method.

vTemperature obtained by the second correction method. 


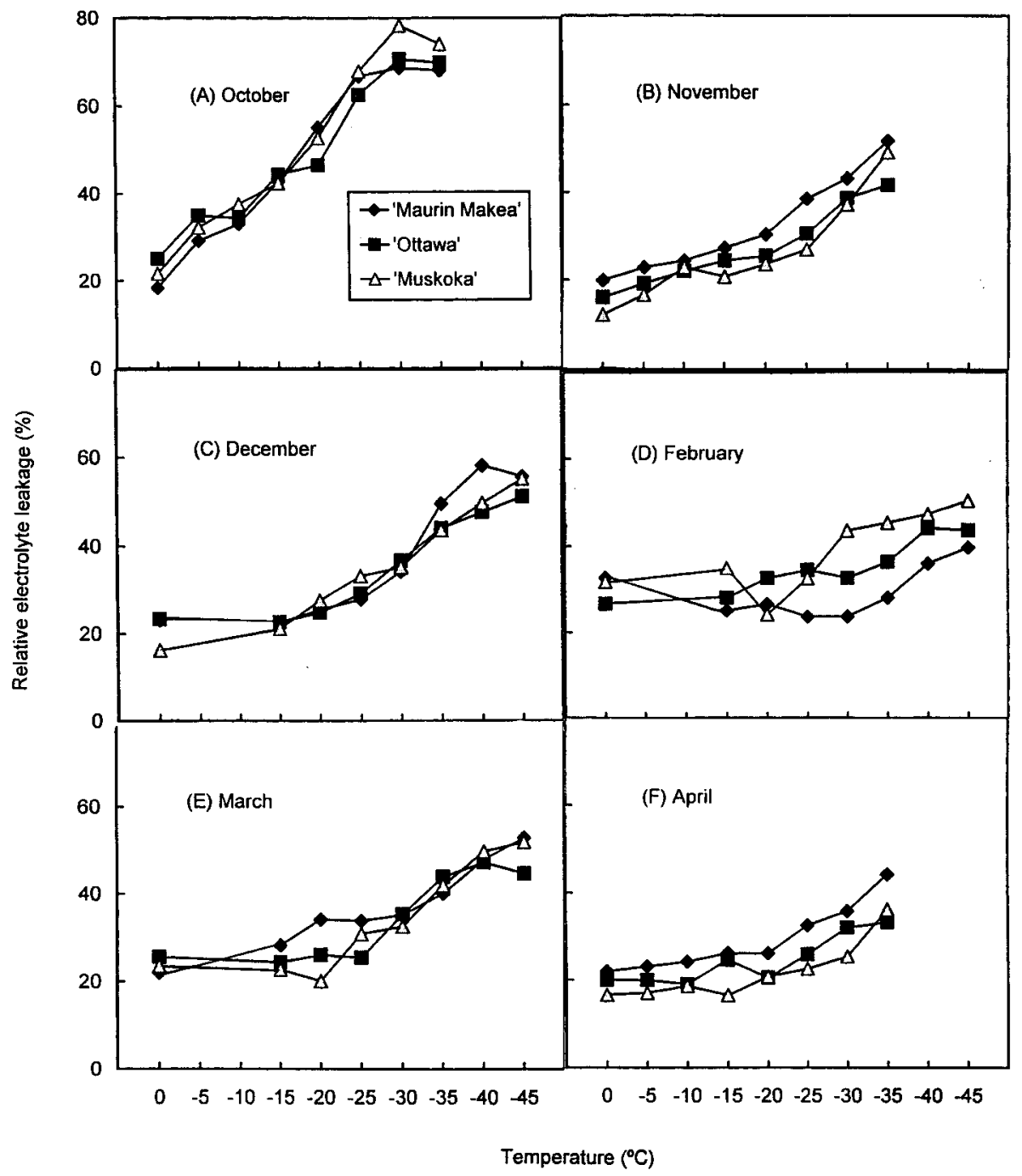

Lim et al., 1998; von Fircks and Verwijst, 1993). Fitting an asymmetric curve to EL data has yielded varying results. In most cases studied by Anisko and Lindstrom (1995), temperature at the inflection point of the Richards function overestimated the lethal-temperature range, while Lim et al. (1998) reported a close agreement between visual $\mathrm{LT}_{50} \mathrm{~S}$ and critical-temperature estimates made by both the Richards and Gompertz functions.

In the present study, the lethal temperature was well predicted by the Gompertz, but not by the Richards function. In addition, we met with several failures in fitting the Richards function to leakage data from raspberry canes. The Richards function is highly nonlinear due to having an additional parameter for shaping curves as compared to the logistic and Gompertz functions. The high nonlinearity in parameters makes the estimation procedure fragile and sensitive to both initial starting values and extreme observations.

While fitting asymmetric functions to percentage-adjusted injury data, both $T_{50}$ and $\mathrm{T}_{\max }$ estimates can be calculated. For raspberry canes, the $T_{50}$ estimate produced by the Gompertz function was correlated better with visual $\mathrm{LT}_{50}(R=0.821)$ than the $\mathrm{T}_{\max }$ estimate $(R=0.785)$. In a study by Lim et al. (1998), the two hardiness estimates predicted the freezing tolerance of rhododendron leaves equally well. Generally, the lethal temperature is assumed to coincide with $\mathrm{T}_{\max }$, the point of the highest rate of change in plant response.

Fig. 1. Seasonal (monthly) fluctuations in the level of freeze-induced relative electrolyte leakage [(initial leakage/final leakage $) \times 100]$ measured from canes of three raspberry cultivars. Each symbol represents the mean of three replicate samples.

of leakage response have used the symmetrical logistic function. For herbaceous plants, using the inflection point of the logistic curve as an indication of lethal temperature has often proved reliable (e.g., Anderson et al., 1988; Janácek and Prásil, 1991; Miller and Dickens, 1996), though contradictory results have also occurred (Cardona et al., 1997; Warren et al., 1996). For woody plants, the method has worked well in assessing temperatureinduced injuries in citrus [Citrus aurantium L., C. sinensis L. (Osbeck.) X Poncirus trifoliata L. (Raf.) and C. paradisi Macf. $\mathrm{X}$ P. trifoliata L. (Raf.)] roots (Ingram and Buchanan, 1984) and olive (Olea europea L.) leaves (Palliotti and Bongi, 1996). However, the lethal temperature of well-acclimated Scots pine (Pinus sylvestris L.) needles was underestimated by analysis of inflection points of logistic curves as compared to visual-injury assessments (Repo et al., 1996). In most of our data sets, the $T_{\max }$ estimations by the logistic curve were in close agreement with visual evaluations.

The main drawback in using the logistic function is its symmetry; an asymmetric model is considered more appropriate for describing plant response to temperature stress in terms of physical and physiological mechanisms (Anisko and Lindstrom, 1995;

Anisko and Lindstrom (1995) achieved an improvement in interpretation of leakage data by using a correction method in connection with the Richards function. Their correction assumes leakage data are transformed to start from zero by using index of injury or percentage-adjusted injury values. We introduced a related but more general correction method that does not require data transformation. In our study, however, the two correction procedures did not bring about any substantial improvement in comparison with the original Richards and Gompertz functions.

For red raspberry canes, curves of leakage vs. freezing temperature were flattened in the course of cold acclimation and dormancy development, rendering curve fitting more difficult. Splitting the samples longitudinally and using vacuum infiltration did not increase the level of leakage (Palonen and Lindén, unpublished data). Apparently, seasonal changes in cell walls and membranes are reflected in the amount of electrolytes diffusing from tissues (Barka and Audran, 1996; Kacperska-Palacz et al., 1977; Sutinen et al., 1992). Poor leaching of electrolytes may cause problems in interpretation of leakage data from wellacclimated woody plants (Anisko and Lindstrom, 1995; Repo et al., 1996; Sutinen et al., 1992).

On the basis of our findings, transformation of data to percentage-adjusted injury suggested by Lim et al. (1998) is recommended while testing acclimated woody plant samples with reduced levels of EL. For theoretical reasons, modeling EL data 
with the asymmetric Gompertz function is preferred to the symmetrical, logistic function. The choice between the two measures of lethal temperature, $\mathrm{T}_{50}$ and $\mathrm{T}_{\max }$, warrants further research. Deriving the lethal temperature by the graphical method proposed by Sutinen et al. (1992) allows for reliable hardiness estimates.

\section{Literature Cited}

Anderson, J.A., M.P. Kenna, and C.M. Taliaferro. 1988. Cold hardiness of 'Midiron' and 'Tifgreen' bermudagrass. HortScience 23:748-750.

Anisko, T. and O.M. Lindstrom. 1995. Applying the Richards function in freezing tolerance determination with electrolyte and phenolic leakage techniques. Physiol. Plant. 95:281-287.

Arora, R., D.S. Pitchay, and B.C. Bearce. 1998. Water-stress-induced heat tolerance in geranium leaf tissues: A possible linkage through stress proteins? Physiol. Plant. 103:24-34.

Arora, R., M.E. Wisniewski, and R. Scorza. 1992. Cold acclimation in genetically related (sibling) deciduous and evergreen peach [Prunus persica (L.) Batsch]. 1. Seasonal changes in cold hardiness and polypeptides of bark and xylem tissues. Plant Physiol. 99:1562-1568.

Barka, E.A. and J.C. Audran. 1996. Utilisation de la conductivité spécifique comme critère d'estimation de la viabilité au niveau de l'appareil aérien des vignes champenoises soumises aux températures negatives. Can. J. Bot. 74:413-418.

Boorse, G.C., T.L. Bosma, A.-C. Meyer, F.W. Ewers, and S.D. Davis. 1998. Comparative methods of estimating freezing temperatures and freezing injury in leaves of chaparral shrubs. Intl. J. Plant Sci. 159:513521.

Calkins, J.B. and B.T. Swanson. 1990. The distinction between living and dead plant tissue-Viability tests in cold hardiness research. Cryobiology 27:194-211.

Cardona, C.A., R.R. Duncan, and O. Lindstrom 1997. Low temperature tolerance assessment in Paspalum. Crop Sci. 37:1283-1291.

Eliason, S.R. 1993. Maximum likelihood estimation, logic and practice. (Sage Univ. Paper Ser. Quantitative Applications Social Sci. 07-096). Sage Publ., Newbury Park, Calif.

Flint, H.L., B.R. Boyce, and D.J. Beattie. 1967. Index of injury-A useful expression of freezing injury to plant tissues as determined by the electrolytic method. Can. J. Plant Sci. 47:229-230.

Grossnickle, S.C. 1992. Relationship between freezing tolerance and shoot water relations of western red cedar. Tree Physiol. 11:229-240.

Hadley, J.L. and R.G. Amundson. 1992. Effects of radiational heating at low air temperature on water balance, cold tolerance, and visible injury of red spruce foliage. Tree Physiol. 11:1-17.

Ingram, D.L. and D.W. Buchanan. 1984. Lethal high temperatures for roots of three citrus rootstocks. J. Amer. Soc. Hort. Sci. 109:189-193.

Janácek, J. and I. Prásil. 1991. Quantification of plant frost injury by nonlinear fitting of an s-shaped function. Cryo-Letters 12:47-52.

Kacperska-Palacz, A., E. Dulgokecka, J. Breitenwald, and B. Wcislinska. 1977. Physiological mechanisms of frost tolerance: Possible role of protein in plant adaptation to cold. Biologia Plant. 19:10-17.

Keates, S.E. 1990. Assessing cold hardiness in conifers: A problem analysis and discussion paper. Can.-Brit. Columbia For. Res. Dev. Agreement Rpt. 106.

Lim, C.C., R. Arora, and E.C. Townsend. 1998. Comparing Gompertz and Richards functions to estimate freezing injury in Rhododendron using electrolyte leakage. J. Amer. Soc. Hort. Sci. 123:246-252.

Lindén, L., H. Rita, and T. Suojala. 1996. Logit models for estimating lethal temperatures in apple. HortScience 31:91-93.

Miller, G.L. and R. Dickens. 1996. Potassium fertilization related to cold resistance in bermudagrass. Crop Sci. 36:1290-1295.

Palliotti, A. and G. Bongi. 1996. Freezing injury in the olive leaf and effects of mefluidide treatment. J. Hort. Sci. 71:57-63.

Palonen, P. and L. Lindén. 1999. Dormancy, cold hardiness, dehardening, and rehardening in selected red raspberry cultivars. J. Amer. Soc. Hort. Sci. 124:341-346.

Palta, J.P., K.G. Jensen, and P.H. Li. 1982. Cell membrane alterations following a slow freeze-thaw cycle: Ion leakage, injury and recovery, p. 221-242. In: P.H. Li and A. Sakai (eds.). Plant cold hardiness and freezing stress. Academic Press, New York.

Rajashekar, C., M.N. Westwood, and M.J. Burke. 1982. Deep supercooling and cold hardiness in genus Pyrus. J. Amer. Soc. Hort. Sci. 107:968-972.

Repo, T., H. Hänninen, and S. Kellomäki. 1996. The effects of long-term elevation of air temperature and $\mathrm{CO}_{2}$ on the frost hardiness of Scots pine. Plant, Cell Environ. 19:209-216.

Sutinen, M.-L., J.P. Palta, and P.B. Reich. 1992. Seasonal differences in freezing stress resistance of needles of Pinus nigra and Pinus resinosa: Evaluation of the electrolyte leakage method. Tree Physiol. 11:241254.

von Fircks, H.A. and T. Verwijst. 1993. Plant viability as a function of temperature stress. The Richards function applied to data from freezing test of growing shoots. Plant Physiol. 103:125-130.

Warren, G., R. McKown, A.-L. Marin, and R. Teutonico. 1996. Isolation of mutations affecting the development of freezing tolerance in Arabidopsis thaliana (L.) Heynh. Plant Physiol. 111:1011-1019.

Wiemken, V., L. Kossatz, and K. Ineichen. 1996. Frost hardiness of Norway spruce grown under elevated atmospheric $\mathrm{CO}_{2}$ and increased nitrogen fertilizing. J. Plant Physiol. 149:433-438.

Zhu, G.H. and Z.Q. Liu. 1987. Determination of median lethal temperature using logistic function, p. 291-298. In: P.H. Li (ed.). Plant cold hardiness. Alan R. Liss, New York. 